\title{
Biochemical Basis for Diagnosis of Theileriosis in Cattle and Buffaloes
}

\author{
Sabhyata Sharma*, S. W. Kolte, Vishaw Vikas and Vaishnavi Dhanorkar \\ Department of Veterinary Parasitology, Nagpur Veterinary College, MAFSU, Nagpur, India \\ *Corresponding author
}

\section{A B S T R A C T}

\begin{tabular}{|c|c|}
\hline & \\
\hline & The study was carried out to assess the status of theileriosis in cattle and buffaloes using \\
\hline $\begin{array}{l}\text { Theileriosis in } \\
\text { Cattle and } \\
\text { Buffaloes, } \\
\text { Theileria annulata }\end{array}$ & $\begin{array}{l}\text { biochemical levels of serum calcium, phosphorous and adenosine deaminase. Cattle and } \\
\text { buffaloes naturally infected with Theileria annulata and Theileria orientalis were examined } \\
\text { through biochemical analysis and the estimates were correlated to determine the severity } \\
\text { of infection, immunological responses and the extent of tissue damage. A total of } 50 \text { cattle }\end{array}$ \\
\hline Article Info & and 50 buffaloes were sampled for the study which included both infected and non- \\
\hline $\begin{array}{l}\text { Accepted: } \\
08 \text { January } 2020 \\
\text { Available Online: } \\
10 \text { February } 2020\end{array}$ & $\begin{array}{l}\text { whereas for adenosine deaminase, chemicals were prepared manually in Veterinary } \\
\text { Parasitology lab, Nagpur, and the activity was estimated using nano-drop } \\
\text { spectrophotometer. }\end{array}$ \\
\hline
\end{tabular}

\section{Introduction}

Theileriosis is one of the most important and frequently occurring fatal tick-borne disease in cattle and buffaloes of tropical regions, including India. Tropical theileriosis, haemoprotozoan disease of ruminants caused by Theileria annulata and Theileria orientalis and transmitted by Hyalomma sp., is a severe and highly economical disease as it causes reduction in milk yield and life time carrier state in bovines. The disease is usually characterised by high temperature, lymph node enlargement, reduction in milk yield, progressive anaemia, lacrimation, hypersalivation, diarrhoea or constipation and in some cases dyspnea also. Since, Theileria annulata and Theileria orientalis are intra- erythroctic parasites, the detection of Calcium, Phosphorous and Adenosine deaminase levels are important bio-markers for host-parasite interaction. Adenosine deaminase, which catalyses the conversion of adenosine to inosine, appears to be important for normal immunological functions. ADA is an enzyme that is present in cells and and is considered as marker of cell mediated immunity as the levels of the enzyme increases in various infectious and lymphoproliferative disease whereas variation in mineral levels indicates the extent of tissue damage, helps in better understanding the pathogenesis of the diseases. The fluctuations in mineral levels in infected animals was probably due to decrease dietary intake, intestinal malfunctions, hypoproteinemia, 
kidney damage or diarrhoea. Thus, biochemical parameters also helps in better understanding the level of disease, prognosis and diagnosis of the theileriosis.

\section{Materials and Methods}

\section{Animal materials}

The study included 50 cattle and 50 buffaloes exhibiting the clinical signs of theileriosis. The samples were collected from the infected group and were analysed in Veterinary Parasitology laboratory of Nagpur Veterinary College, Nagpur, Maharashtra, India. All the animals used in the study were female bovines, aged between 2-8 years and were of breed HF, Jersey, Murrah and indigenous cattle.

\section{Study design}

The infected animals were selected on the basis of clinical signs. The clinical symptoms observed were high temperature, lymph node enlargement, hypersalivation, hyperlacrimation, anorexia, emaciation, reduced milk yield, diarrhoea, constipation, depression, exopthalmia, anaemia and petechial haemorrhages in eye. Blood smears were also prepared from jugular vein of all the animals and were stained with Giemsa's stain to confirm theileriosis microscopically. On microscopic examination, slides revealed the presence of piroplasms of Theileria annulata and Koch blue bodies in the R.BC's and lymphocytes, respectively.

\section{Collection of Samples}

The serum samples from 50 cattle and 50 buffaloes infected with theileriosis were collected from jugular vein into the plain vials without anticoagulant. For biochemical analysis, the serum was separated by centrifugation at $3000 \mathrm{rpm} /$ minute and stored at $-20^{\circ} \mathrm{C}$.

\section{Chemical preparation}

For Calcium and Phosphorous estimation, commercial kits were used, manufactured by Coral clinical systems, Goa whereas for Adenosine deaminase estimation, chemicals were prepared manually in laboratory. For adenosine deaminase estimation, $0.028 \mathrm{gm}$ of adenosine was weighed in a sterilised beaker and dissolved in $5 \mathrm{ml}$ of Phosphate buffer saline.

For working standard, $0.991 \mathrm{gm}$ of ammonium sulphate was added in $50 \mathrm{ml}$ of distilled water. Later the test tubes were named as Blank, Standard and Sample were incubated at $37^{\circ} \mathrm{C}$ for 1 hour. $1.5 \mathrm{ml}$ of phenol and alkaline hypochlorite was also added to each tube and incubated. The absorbance of Calcium, Phosphorous and Adenosine deaminase was recorded spectrophotometrically at $570 \mathrm{~nm}$, $340 \mathrm{~nm}$ and $620 \mathrm{~nm}$, respectively.

\section{Statistical analysis}

For statistical analysis, Student's t-test was used to determine the difference between the infected group and the control group

\section{Results and Discussion}

In the analysis of serum of infected animals, when compared with controls, it was found that there was stastically significant increase in Adenosine deaminase levels. On the other hand, significant decrease was seen in the mean serum components of Calcium and Phosphorous. Additionally, changes in serum biochemical parameters in infected and control group are given in Table 1 . 
Table.1 Effect of tropical theileriosis on mean selected serum biochemical parameters in Bovine

\begin{tabular}{|l|l|l|l|l|}
\hline Parameter & Unit & Infected group & Non-infected group & Significance (p) \\
\hline Calcium & $\mathrm{mg} / \mathrm{dl}$ & $3.90 \pm 0.27$ & $5.25 \pm 0.41$ & $\mathrm{p}=0.008$ \\
\hline Phosphorous & $\mathrm{mg} / \mathrm{dl}$ & $2.78 \pm 0.14$ & $3.36 \pm 0.19$ & $\mathrm{p}=0.02$ \\
\hline ADA & $\mathrm{IU} / \mathrm{L}$ & $39.20 \pm 1.30$ & $18.58 \pm 2.90$ & $\mathrm{p}=0.04$ \\
\hline
\end{tabular}

Tropical bovine theileriosis is a highly pathogenic and fatal disease of cattle transmitted by ticks of genus Hyalomma (Gul et al., 2015). This parasite is responsible for heavy mortality and morbidity with substantial reduction in milk yield. In India, the disease has been reported from various geographical regions like Punjab, Haryana, Gujrat, Maharashtra and other humid areas, as the disease proliferates in hot and humid climate and is favourable for transmission of infection (Kohli et al., 2014). The disease has got economical importance as it causes decrease in milk production and life time carrier state in recovered animals (Kumar et $a l ., 2018)$. The clinical signs observed in the present study were found similar to the signs of other reports (Durrani et al., 2008; Mahmmod et al., 2010; Ghanem et al., 2013; Khatoon et al., 2015 and Soulsby., 1982).

Serum biochemistry plays a very important role in understanding the severity of the infection, and is a very good tool for diagnosis, prognosis and evaluation of the therapy applied. In the present study significant decrease in serum Calcium and Phosphorous levels in infected animals as compared to control group were consistent with the data reported by Omer et al., 2003; Col and Uslu., 2007; Hasanpour et al., 2008; Saber et al., 2008 and Lawrence et al., 2018. In the present study hypocalcemia in bovine was reported probably due to hypoproteinemia, liver malfunctions, decreased dietary intake and intestinal malfunction whereas Hypophosphatemia was reported to be due to renal wasting, diarrhoea which causes loss of minerals from the body.
Adenosine deaminase plays a crucial role in monocyte-lymphocyte proliferation (Altug and Agaoglu., 2007). It has been reported that there is positive relationship between increased cellular response, lymphoreticular cell activity and ADA activity. Therefore, ADA is now considered as marker of cell mediated immunity as its level increases in various infectious and lymphoproliferative disease.The increase in ADA levels is known to be due to lymphoproliferation of T-cells by schizont infected cells (Altug et al., 2008). As a result, increased Adenosine deaminase activity in tropical bovine theileriosis is most likely a cell mediated response, in order to protect the lymphocytes from parasitic attack.

\section{References}

Abdela, N., \&Bekele, T. (2016). Bovine theileriosis and its control: a review. AdvBiol Res, 10(4), 200-12.

Abdela, N., \&Bekele, T. (2016). Epidemiology and Control of Bovine Theileriosis in Ethiopia: Review. Journal of Medicine, Physiology and Biophysics, Vol.23.

Altug, N., \&Agaoglu, Z. T. (2007). Investigation on the relationship between lymphocyte subsets, immunoglobulin levels and adenosine deaminase activities in immunosuppressive dose methylprednisolone treated dogs. Bulletin- Veterinary institute in Pulawy, 51(1), 109.

Altuğ, N., Yüksek, N., Ağaoğlu, Z. T., \&Keleş, İ. (2008). Determination of 
adenosine deaminase activity in cattle naturally infected with Theileria annulata. Tropical animal health and production, 40(6), 449-456.

Col, R., \&Uslu, U. (2007). Changes in selected serum components in cattle naturally infected with Theileria annulata. Bulletin-veterinary institute in Pulaway, 51(1), 15.

Demessie, Y., \&Derso, S. (2015). Tick borne hemoparasitic diseases of ruminants: A review. Advances in Biological Research, 9(4), 210-224.

Durrani, A. Z., Ahmad, M., Ashraf, M., Khan, M. S., Khan, J. A., Kamal, N., \&Mumtaz, N. (2008). Prevalence of theileriosis in buffaloes and detection through blood smear examination and polymerase chain reaction test in district Lahore. J Anim Plant Sci, 18, 59-62.

Gul, N., Ayaz, S., Gul, I., Adnan, M., Shams, S., \&ul Akbar, N. (2015). Tropical theileriosis and east coast fever in cattle: present, past and future perspective. Int $\mathbf{J}$ CurrMicrobiol App Sci, 4, 1000-1018.

Ghanem, M. M., Abdelhamid, O. M., \&Bakir, N. M. (2013).Clinico-Biochemical, Serological and Molecular Study on Tropical Theileriosis in Egyptian Water Buffaloes (BubalusBubalis).www. alexjvs. Com Hasanpour, A., Moghaddam, G. A., \&Nematollahi, A. (2008). Biochemical, hematological, and electrocardiographic changes in buffaloes naturally infected with Theileria annulata. The Korean journal of parasitology, 46(4), 165-169.

Khatoon, S., Kolte, S. W., Kurkure, N. V., Chopde, N. A., \&Jahan, A. (2015). Detection of tropical bovine theileriosis by polymerase chain reaction in cattle.Journal of parasitic diseases, 39(1), 53-56.
Kohli, S., Atheya, U. K. and Thapliyal, A. (2014). Prevalence of theileriosis in cross-bred cattle: Its detection through blood smear examination and polymerase chain reaction in Dehradun district, Uttarakhand, India. Veterinary world, 7(3), 168-171.

Kumar, S., Mohmad, A., Parthsarthi, B. C., Fular, A., Gupta, S., Singh, D. (2018).Current Epidemiological Status of Bovine Theileriosis in Indian Scenario. Ann ClinCytolPathol 4(1): 1090.

Lawrence, K. E., Forsyth, S. F., Vaatstra, B. L., McFadden, A. M. J., Pulford, D. J., Govindaraju, K., \&Pomroy, W. E. (2018). Clinical haematology and biochemistry profiles of cattle naturally infected with Theileria orientalis Ikeda type in New Zealand. New Zealand veterinary journal, 66(1), 21-29.

Mohammed-Ahmed, G. M., Hassan, S. M., El Hussein, A. M., \&Salih, D. A. (2018).Molecular, serological and parasitological survey of Theileria annulata in North Kordofan State, Sudan. Veterinary Parasitology: Regional Studies and Reports, 13, 2429.

Mahmmod, Y. S., El-Balkemy, F. A., Yuan, Z. G., El-Mekkawy, M. F., Monazie, A. M., \& Zhu, X. Q. (2010). Field evaluation of PCR assays for the diagnosis of tropical theileriosis in cattle and water buffaloes in Egypt. Journal of Animal and Veterinary Advances, 9(4), 696-699.

Omer, O. H., El-Malik, K. H., Magzoub, M., Mahmoud, O. M., Haroun, E. M., Hawas, A., \& Omar, H. M. (2003). Biochemical profiles in Friesian cattle naturally infected with Theileria annulata in Saudi Arabia. Veterinary research communications, 27(1), 1525. 
Soulsby, E. J. L. (1982) Helminths, Arthropods and Protozoa of Domestic Animals, 7th EdnBailliereTindail,

(2008). Evaluation of Elseveir.

Saber, A, P, .R.,Khorrani, M., Nouri, M. haematochemical parameters in crossbred cattle naturally infected with Theileria annulata in Iran. Int. J. Dairy Sci., 3(4): 205-209.

\section{How to cite this article:}

Sabhyata Sharma, S. W. Kolte,Vishaw Vikas and Vaishnavi Dhanorkar. 2020. Biochemical Basis for Diagnosis of Theileriosis in Cattle and Buffaloes. Int.J.Curr.Microbiol.App.Sci. 9(02): 1212-1216. doi: https://doi.org/10.20546/ijcmas.2020.902.143 